\title{
Molecular Diversity: a new scope and path for 2009 and on
}

\author{
Guillermo A. Morales
}

Published online: 6 January 2009

(c) Springer Science+Business Media B.V. 2009

In mid 2007 Molecular Diversity (MODI) underwent an editorial management transition with the implementation of a new Editor in Chief and a team of Associate Editors.

With the support and guidance of MODI's Editorial Advisory Board and Springer, we began the process of rebuilding and modernizing MODI. We reviewed the progress, scope, infrastructure, current status of our journal, identified our weaknesses and deficiencies, and set a plan to address those issues to improve our journal.

I would like to share with you the results of this review.

Currently, MODI is abstracted/indexed in the following databases:

\begin{tabular}{ll} 
- $\begin{array}{l}\text { Biochemistry and } \\
\text { Biophysics Citation } \\
\text { Index }\end{array}$ & Biological Abstracts \\
- Chemical Abstracts & $\bullet$ Chemistry Citation Index \\
Service & \\
- Current Contents/ Life & $\bullet$ EMBASE \\
Sciences & \\
- Index & ISI Alerting Services \\
Medicus/MEDLINE & \\
- Science Citation Index & $\bullet$ SCOPUS \\
Expanded (SciSearch) & \\
\hline
\end{tabular}

For 2007, MODI regained a competitive Impact Factor status: 2.708 .

In 1995 Molecular Diversity emerged as the first journal completely dedicated to the field that revolutionized research as we know it: Combinatorial Chemistry.

The first editorial entitled "Molecular diversity comes of age !" began and ended with the following two statements

G. A. Morales ( $\square)$

Semafore Pharmaceuticals Inc., 8496 Georgetown Road, Indianapolis, IN 46268, USA

e-mail: Editor@Molecular-Diversity.com in order: (1) "A new field of research, termed 'molecular diversity', has taken the chemical and biological sciences by storm over the last five years.", and (2) "It is our intent to guide Molecular Diversity to fairly reflect the power of these new technologies. Please join us in our efforts to make this the premier forum for this exciting new field."

Since then several key emerging technologies have also come to age with a tremendous positive impact in chemical and biological sciences for the design, analysis and generation of new chemical entities and molecular diversity, such as:
- Microwave Synthesis

- Flow Synthesis

- Nano-reactors

- Computational Chemistry

- Chemoinformatics and QSAR
- Fluorous Synthesis

- Diversity Oriented Synthesis (DOS)

- Click Chemistry

- Analytical and Purification Techniques

- Fragment- and Ligand-Based Design
Recognizing both these advances and advances yet to come, Molecular Diversity is broadening its scope to cover and include these topics and related research areas.

In addition to research articles and reviews, MODI will also begin to accept and include perspectives, mini-reviews, expert opinions, short communications, letters to the Editor, and special issues. In 2009, we will launch sections written by our Editorial Members covering recent important/relevant publications and scientific breakthroughs.

As part of our efforts to improve MODI and to help authors publish their work quickly, we are also shortening the submission-revision-publication cycle, allowing a much faster publication timeline compared to other journals.

When we receive corrected proofs, the manuscripts are published to Online First ${ }^{\mathrm{TM}}$ approximately 1 week later. 
In addition, when a manuscript is published Online First $^{\mathrm{TM}}$, it becomes an official publication and is citable with the DOI system.

Moreover, we are actively reaching out to recognized researchers, research groups, and the scientific community to bring MODI to their attention and invite them to publish their work and breakthroughs with us.

We are also dedicating special issues to high-impact and relevant conferences covering their presentations (Note: material submitted for publication will undergo normal peerreview process). The 2 conferences we are working with are:

- 4th International Conference on

Multicomponent

Reactions

(MCR2009) May

24-28, 2009

Ekaterinburg, Russia

Homepage: http://

www.mcr2009.ru
- 2nd International Symposium on

Combinatorial Sciences in Biology, Chemistry, Catalysts and Materials (SCS-09) Sept. 19-22, 2009 Beijing, China Homepage: http://www. scs09.com
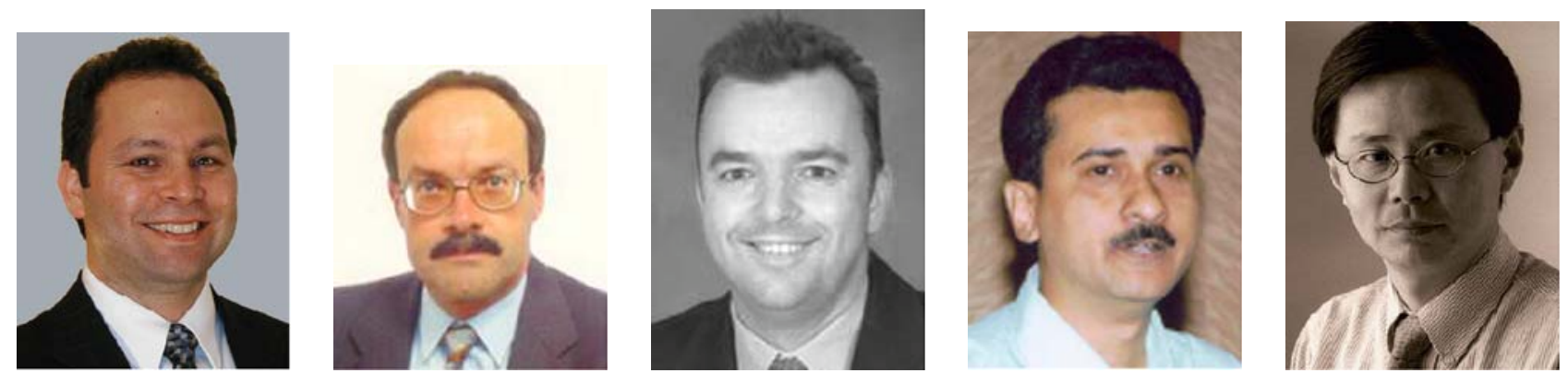

From left to right: Guillermo A. Morales (Editor-in-Chief), Eduard Felder, Chris Hulme, Kunal Roy, and Wei Zhang (Associate Editors). 